\title{
Synthesis of Elements and Solid Structures in Atomic-Nuclear Reactions in Dense Gases and Dense Gas-Metal Systems as a Result of Gamma Quanta Irradiation
}

\author{
T. WilczyŃSKA ${ }^{a, *}$, G. Mishinsky ${ }^{b}$ AND R. WiśnieWski ${ }^{a, c, d}$ \\ ${ }^{a}$ National Centre for Nuclear Research, Otwock-Świerk, Poland \\ ${ }^{b}$ Joint Institute for Nuclear Research, Dubna, Russia \\ ${ }^{c}$ Warsaw University of Technology, Physics Faculty, Warsaw, Poland \\ ${ }^{d}$ Institute of Agricultural and Food Biotechnology, Warsaw, Poland
}

Doi: 10.12693/APhysPolA.139.438 *e-mail: teresa.wilczynska@gmail.com

\begin{abstract}
New effects observed in irradiated dense gas-metal systems (e.g. $\mathrm{D}_{2}-\mathrm{Pd}$ ) and the effects of irradiation of pure dense gases $\left.\left(\mathrm{H}_{2}, \mathrm{D}_{2}, \mathrm{He}, \mathrm{Xe}\right) 10 \mathrm{MeV}\right)$ are presented in this paper. The gas-metal systems were irradiated by braking gamma quanta with threshold energy slightly below $10 \mathrm{MeV}$ and energy of about $25 \mathrm{MeV}$ (giant dipole nuclear resonance). In all considered cases, the time of irradiation was of the order of $10^{5} \mathrm{~s}$. The intensity of gamma quanta flux of about $10^{14} / \mathrm{s}$, (generated by electron current of about $20 \mu \mathrm{A}$ in used accelerators), was also large. Experimental procedures were realized as follows: gas in room temperature was compressed to high pressure (1-3 kbar) in a beryllium bronze pressure chamber or in stainless steel high pressure capillary with chosen metal samples inside or without any samples. Then, the systems were irradiated. In all cases, new objects appeared which contained in relatively large amounts - such light elements as $\mathrm{C}$ and $\mathrm{O}$, and heavy ones, such as $\mathrm{Pb}, \mathrm{Bi}, \mathrm{Pa}$, that were absent before irradiation. At giant dipole nuclear resonance with $\mathrm{Pd}, \mathrm{V}$, and other metals, such unexpected phenomena were also observed as shape changes, "micro-protuberances", micro objects of specific element contents and cracks of specimen surfaces. The mechanism of the observed effects (i.e., the fission-fusion nuclear reactions initiated by gamma irradiation) remains an open problem. A possible solution, basing on the "trans-nuclear molecule-multinuclear reaction" concept in the case of carbon-rich objects obtained due to gamma irradiation of the pure dense gaseous helium, is shortly described.
\end{abstract}

topics: $\gamma$ irradiation, high pressure, $\mathrm{D}_{2}, \mathrm{He}, \mathrm{Xe}$

\section{Introduction}

Studies of hydrogen(deuterium)-metal systems under high-pressure were conducted many years ago, in 1964, as part of the collaboration between Professor R. Wiśniewski (Physics Faculty, WUT) and Professor B. Baranowski (Physical Chemistry Institute, Polish Academy of Sciences). In particular, when Wiśniewski studied the solubility of deuterium in the palladium foil using the first in the world gas $\mathrm{H}_{2}$ high-pressure apparatus (up to $p=28$ kbar) designed by him, a strong explosion took place. The cause of that explosion could not be explained by chemical reactions or accumulated compression energy, which occurred in deuterium at $p=22$ kbar. Therefore, a decision was made to repeat the experiment using simultaneous $\gamma$ quanta irradiation in order to obtain the atomic state of deuterium (to increase its chemical activity).

Such studies were undertaken in 2004, in cooperation with JINR Dubna (Professor A.Yu. Didyk), with braking $\gamma$-rays irradiation in the energy regime up to $10 \mathrm{MeV}$ and up to $30 \mathrm{MeV}$ (before, and in terms of giant dipole nuclear resonance (GDNR) of selected metals in the atmosphere of dense gases such as $\left.\mathrm{H}_{2}, \mathrm{D}_{2}\right)$. This appeared to be very novel because of the synthesis of new micro and macro objects (that can be used as a basis of the new nanotechnology), changes in the shape of the investigated samples and "micro-protuberance" from the surface with original compositions (that can be generated by new unknown nuclear-physics reactions). Subsequent investigations with pure gases $\mathrm{H}_{2}, \mathrm{D}_{2}$, $\mathrm{He}$, and $\mathrm{Xe}$ (of pollution level up to $15 \mathrm{ppm}$ ), giving unexpected results, confirmed the uniqueness of these studies.

The used high-pressure apparatus was made of beryllium bronze or of high quality austenitic stainless steel for reasons of hydrogen brittleness. Research was conducted, despite adverse circumstances (small active cross-sections for probably nuclear reactions), leading to a formation of new elements, in the beginning not observed in large amounts in the research specimens. 
(a)

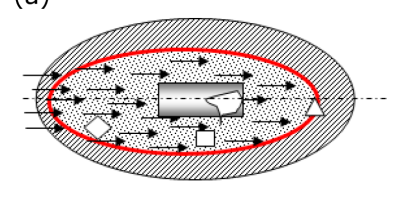

(b)

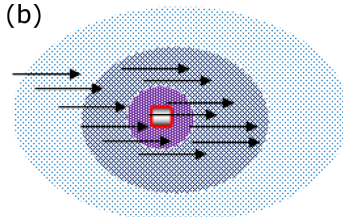

Fig. 1. Simplified model of conducted experiments: (a) at some container, and (b) at expected giant gaseous object in the cosmos - with or without solid element in the center - irradiated incidentally by proper cosmic $\gamma$ irradiation.

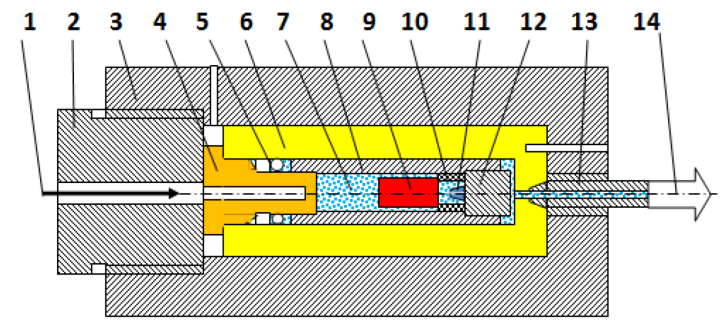

Fig. 2. Schematic of elements of the high pressure apparatus (DHPC) used in our first experiment: 1 - $\gamma$-quanta, 2 - closing screw with hole, 3 - reinforcing high pressure chamber body, 4 - $\mathrm{Cu}_{0.98} \mathrm{Be}_{0.02}$ "window" plug, 5 - high pressure seals, $6-\mathrm{CuBe} 2$ high pressure chamber, 7 - (hydrogen) deuterium under high pressure, 8 - brass sleeve, 9 - investigated $\mathrm{Pd} \operatorname{rod}, 10$ - distance manganin sleeve, 11 - expected reaction product, 12 - brass screw, 13 - high pressure connecting capillary, 14 - high pressure valve, strain gauge pressure sensor and gas filling inlet.

Analysis of the composition, surfaces and internal structures of the obtained objects in our experiments was carried out using many methods and in different laboratories. A simplified model of the conducted experiments is shown in Fig. 1. The arrows represent a high-energy gamma stream passing through an inlet port of a pressure shell. The polygon symbol denotes central object changes. The square symbol, in turn, denotes objects which were observed inside the chamber. The triangle symbol describes changes in the inner element (red line) and separates the gas from the pressure shell, see Fig. 1a. Similar situations can exist in the cosmos for a complex object, like in Fig. 1b, or in specific giant gaseous systems. It is not excluded that some other effects observed in our experiment and described here also occur in cosmic space.

Examples of a transportable high-pressure apparatus used in our experiments and photos of the electron accelerator Microtron MT 25 located in N.G. Florov Laboratory for Nuclear Reaction of JINR, Dubna, are shown in Figs. 2 and 3 . Intense braking $\gamma$ radiation (obtained using tungsten target, thickness $2.5 \mathrm{~mm}$ ) with electron current $(10-24 \mu \mathrm{A})$, long exposure times $\left(\approx 10^{5} \mathrm{~s}\right)$ was applied. Almost all experimental systems were

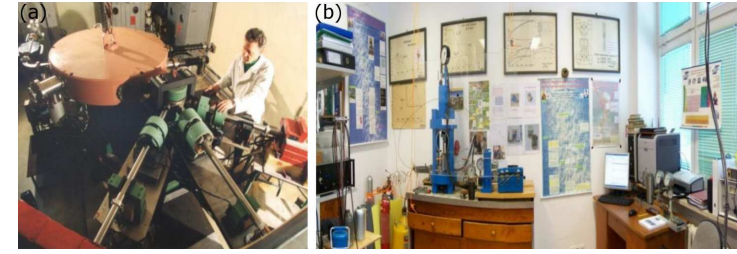

Fig. 3. Photos of (a) the electron accelerator (Microtron MT 25) and (b) HP Laboratory in NCNR (2014).

prepared in Poland while nearly all irradiation procedures, effects registration and discussions took place in different Russian scientific institutions.

Tests on the following systems have been carried out [1]:

- Simple systems $\mathrm{Pd}-\mathrm{D}_{2}, \mathrm{Pd}-\mathrm{H}_{2}$ classic type of high pressure chamber (CTHPC).

- Double system $\mathrm{Pd}-\mathrm{Re}-\mathrm{D}_{2}$, finger type $\mathrm{HPC}$ (FTHPC), GDNR.

- Double systems $\mathrm{Al}-\mathrm{YMn}_{2}-\mathrm{D}_{2}, \mathrm{~V}-\mathrm{Cu}-\mathrm{D}_{2}$, FTHPC, GDNR.

- Complex system $\mathrm{Al}-\mathrm{YMn}_{2}-\mathrm{Al}-\mathrm{YMn}_{2}-\mathrm{Cu}-$ $\mathrm{SS}^{-} \mathrm{D}_{2}$, FTHPC, GDNR.

- Complex system $\mathrm{Sn}-\mathrm{Mo}-\mathrm{Fe}-\mathrm{Ni}-\mathrm{Bi}-\mathrm{Ta}-\mathrm{Cu}-$ $\mathrm{H}_{2}$, CTHPC.

- Pure helium, CTHPC.

- Pure hydrogen, deuterium, xenon, CTHPC [2].

- Mixture of $\mathrm{He}-\mathrm{D}_{2}$ (about 50/50 wt\%), CTHPC [3].

- Simple system $\mathrm{H}_{2}-\mathrm{Pd}$ with gamma and electron irradiations (Dubna Oscillations [1]).

- Mixture of $\mathrm{He}-\mathrm{D}_{2}$ with electrons of $10 \mathrm{MeV}$ energy [4].

In this review, the gamma irradiation investigations in metal-dense gas systems are presented on the example of $\mathrm{Pd}-\mathrm{D}_{2}, \mathrm{Pd}-\mathrm{H}_{2}(10 \mathrm{MeV}), \mathrm{Pd}-\mathrm{Re}-$ $\mathrm{D}_{2}(24 \mathrm{MeV})$, and in pure dense gases - on the examples of $\mathrm{H}_{2}, \mathrm{D}_{2}$ as well as $\mathrm{He}$ and $\mathrm{Xe}(10 \mathrm{MeV})$.

\section{Effects observed in $\mathrm{D}_{2}$ and $\mathbf{P d}$}

Information presented here was based on the first experiment [1], i.e., on the irradiation process of a $\mathrm{Pd}-\mathrm{D}_{2}$ system under pressure of gaseous deuterium of about $3 \mathrm{kbar}$. During the whole time of deuterium HPC (DHPC) exposure to $\gamma$-quanta $t \approx 2.22 \times 10^{4} \mathrm{~s}$, the average current of the electron beam was $\approx 7 \mu \mathrm{A}$. The total number of neutrons $n$ and protons $p$ produced by $\gamma$-quanta per experiment was $N_{\mathrm{n}+\mathrm{p}}=3.23 \times 10^{10}$. During the irradiation by $\gamma$-quanta, the DHPC was cooled by a flux of compressed air at temperature $\approx 20^{\circ} \mathrm{C}$, nevertheless, the temperature of the DHPC external surface significantly exceeded $100^{\circ} \mathrm{C}$. 


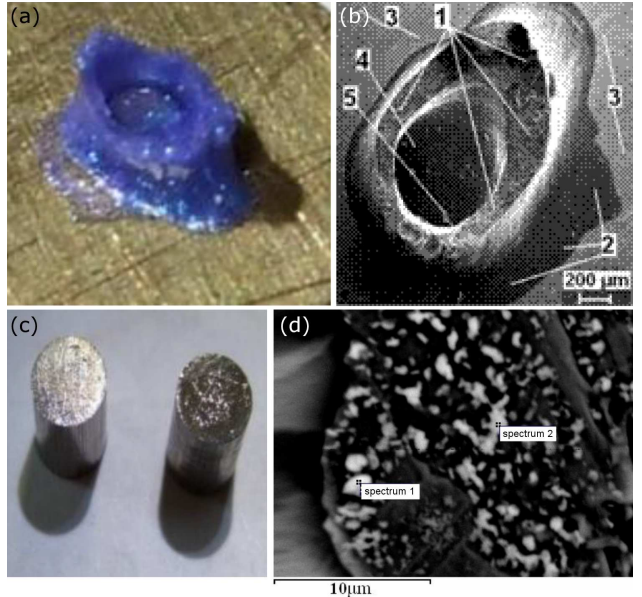

Fig. 4. Photos show: (a) the brass screw with the synthesized novel object (SNO), (b) "volcano" image with the SNO made by scanning electron microscopy, (c) the Pd-rod specimen before and after irradiation - black surface view - which was close to SNO, (d) example of generation of heavy elements on $\mathrm{Pd}-\mathrm{D}_{2}-\gamma$ irradiation (left) and on the black Pd surface (right). The mean value of elements in two measure points, rich with $\mathrm{Pb}$, is as follows: ${ }_{82} \mathrm{~Pb}-47 \%,{ }_{16} \mathrm{O}-20 \%,{ }_{29} \mathrm{Cu}-15 \%$, ${ }_{30} \mathrm{Zn}-9 \%$ and ${ }_{46} \mathrm{Pd}-$ only $8 \%$.

Prior to the opening of the DHPC, some hold-up time aimed to decrease induced activity was necessary. The Pd rod with the external initial diameter of $3.8 \mathrm{~mm}$ was found to be wedged due to its increased overall dimensions inside the brass sleeve with the inside diameter $d=4 \mathrm{~mm}$. After three days, the palladium specimen decreased in size and was easily extracted. A relative diameter change, $\frac{0.2}{4} \times 100 \%=5 \%$, was caused by other than the normal volume change related to beta phase appearance in the $\mathrm{PdH}_{x}\left(\mathrm{D}_{x}\right)$ system.

On the flat inside surface of the brass screw (see Fig. 2, element 12), a synthesized novel object (SNO) - informally called "Annavite" — was discovered. The optical and scanning electron microscopy (SEM) images of this object are presented in Fig. 4a and b. Because of high value of dielectric permeability, the surfaces of the SNO object and brass screw were covered with a thin gold layer of thickness up to $1000 \AA$.

Element compositions $x$ (given in wt\%) in many points of the experimental set after irradiation were determined. For example, a given element composition on the top of the SNO object for four measured points $(1,2,3,4)$ seen in Fig. $4 \mathrm{~b}$ is:

$$
\begin{aligned}
& \text { 1: } \mathrm{C}^{6}(26.81 \%), \quad \operatorname{Mg}^{12}(0.44 \%), \mathrm{Al}^{13}(5.27 \%) \text {, } \\
& \mathrm{O}^{8}(37.78 \%), \quad \mathrm{K}^{19}(1.7 \%), \quad \mathrm{Ca}^{20}(0.31 \%), \\
& \mathrm{Ti}^{22}\left(13.17(\%), \mathrm{Fe}^{26}(0.31 \%), \mathrm{Cu}^{29}(1.17 \%)\right. \text {, } \\
& \mathrm{Zn}^{30}(0.67 \%), \quad \mathrm{Au}^{79}(5.49 \%) \text {; } \\
& \text { 2: } \mathrm{C}^{6}(50.5 \%), \quad \mathrm{O}^{8}(38.43 \%), \quad \mathrm{Mg}^{12}(1.62 \%) \text {, } \\
& \mathrm{Si}^{14}(2.92 \%), \quad \mathrm{Ti}^{22}(0.32 \%), \mathrm{Zn}^{30}(0.81 \%), \\
& \mathrm{Au}^{79}(5.39 \%) \text {; }
\end{aligned}
$$

$$
\begin{aligned}
& \text { 3: } \mathrm{C}^{6}(38.51 \%), \mathrm{O}^{8}(26.35 \%), \quad \mathrm{Mg}^{12}(0.74 \%) \text {, } \\
& \mathrm{Al}^{13}(4.81 \%), \mathrm{Si}^{14}(7.36 \%), \quad \mathrm{Cl}^{17}(0.27 \%) \text {, } \\
& \mathrm{K}^{19}(1.76 \%), \mathrm{Ti}^{22}(9.73 \%), \mathrm{Cu}^{29}(0.7 \%) \text {, } \\
& \mathrm{Zn}^{30}(0.83 \%), \mathrm{Au}^{79}(8.93 \%) \text {; } \\
& \text { 4: } \mathrm{C}^{6}(56.69 \%), \quad \mathrm{O}^{8}(30.39 \%), \mathrm{Mg}^{12}(1.7 \%) \text {, } \\
& \mathrm{Al}^{13}(0.89 \%), \mathrm{Si}^{14}(4.03 \%), \mathrm{K}^{19}(0.28 \%) \text {, } \\
& \mathrm{Ti}^{22}(2.54 \%), \mathrm{Zn}^{30}(0.67 \%), \mathrm{Au}^{79}(2.81 \%) \text {. }
\end{aligned}
$$

The surface studies of both $\mathrm{Pd}$ rods were carried out before and after irradiation. The dark surface object of the irradiated Pd-rod edge, which was close to SNO, is presented in Fig. 4c.

The example of element analysis of the Pd-rod edge (given in wt\%) of seven measured points is as follows:

$$
\begin{aligned}
& \text { 1: } \mathrm{O}^{8}(14.64 \%), \quad \mathrm{Si}^{14}(0.65 \%), \quad \mathrm{S}^{16}(1.08 \%) \text {, } \\
& \mathrm{Ca}^{20}(0.71 \%), \quad \mathrm{Ti}^{22}(1.38 \%), \quad \mathrm{Cu}^{29}(8.29 \%) \text {, } \\
& \mathrm{Zn}^{30}(3.81 \%), \quad \operatorname{Pd}^{46}(25.66 \%) \text {; } \\
& \text { 2: } \mathrm{O}^{8}(22.76 \%), \quad \mathrm{Al}^{13}(3.37 \%), \quad \mathrm{Si}^{14}(3.4 \%) \text {, } \\
& \mathrm{K}^{19}(0.54 \%), \quad \mathrm{Ti}^{22}(11.61 \%), \mathrm{Cu}^{29}(31.20 \%) \text {, } \\
& \mathrm{Zn}^{30}(10.41 \%), \mathrm{Pd}^{46}(10.71 \%) \text {. }
\end{aligned}
$$

A very specific situation, i.e., a large amount of $\mathrm{Pb}$ element, is shown in Fig. 4d.

The entire Pd-rod object turned into an inhomogeneous one which is composed of separate clusters with different element compositions.

In the main part of SNO, the following content of elements (in wt\%) can be determined:

$$
\begin{array}{lll}
\mathrm{C}^{6}(25.08 \%), & \mathrm{O}^{8}(35.60 \%), & \mathrm{Na}^{11}(0.78 \%), \\
\mathrm{Mg}^{12}(1.77 \%), & \mathrm{Al}^{13}(4.88 \%), & \mathrm{Si}^{16}(5.41 \%), \\
\mathrm{K}^{19}(1.51 \%), & \mathrm{Ti}^{22}(13.07 \%), & \mathrm{Cu}^{29}(1.44 \%), \\
\mathrm{Zn}^{30}(0.47 \%), & \mathrm{Au}^{79}(7.60 \%) .
\end{array}
$$

SNO presented a mixed system of four phases: $\mathrm{TiO}_{2}$ - titanium dioxide, $\mathrm{Pd}_{1.5} \mathrm{D}_{2}-$ deuteride palladium, SiTiO-like titanium quartz phase and about $30 \%$ of amorphous phase.

Results of $\gamma$-ray irradiation in the hydrogen high pressure chamber (HHPC), filled up with molecular $\mathrm{H}_{2}$ under pressure $p=0.5 \mathrm{kbar}$ with a $\mathrm{Pd}$ rod inside, appeared very interesting, although the situation in the system of $\mathrm{Pd}-\mathrm{D}_{2}-\gamma$ seems to be completely different. We have obtained many small objects there and one - model — not bonded to any part of the system (see Fig. 5).

\section{Metal composition changes in $\mathrm{D}_{2}$ system}

The experiments carried out by the authors showed the extraordinary efficiency of the nuclear processes taking place and the accompanying physical-chemical processes, which significantly exceed the efficiency of the phenomena observed at a maximum $\gamma$ energy of $10 \mathrm{MeV}$. All these is related to the mechanisms accompanying the GDNR of the exposed nuclei. 

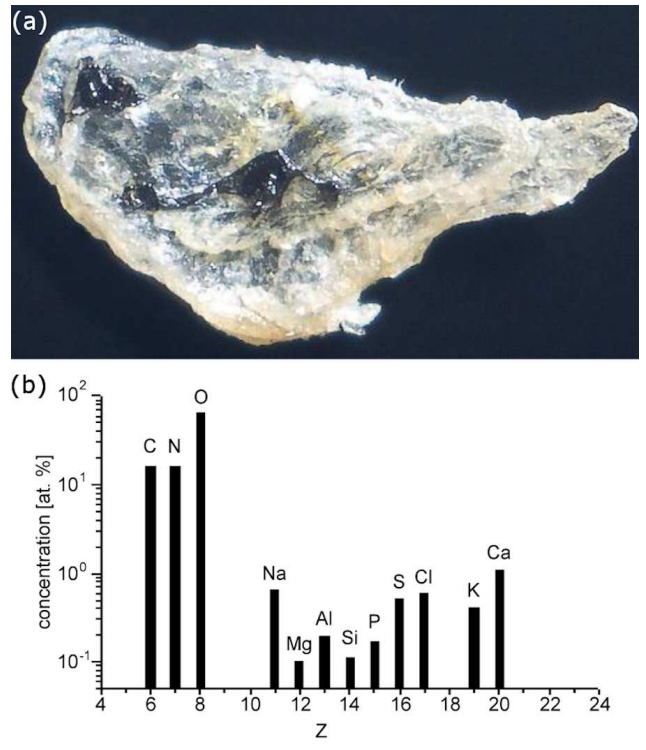

Fig. 5. A large-dimension colored solid object, informally called Tevilkite $(1.50 \times 0.75 \mathrm{~mm})$, and its element content.

We announced these results at the 42nd Congress of Polish Physicists in Poznań [5]. We will not comment here on the reaction of the Polish physicists' community. We only cite characteristic, distinctive, effects, namely the change of dimensions and shapes of irradiated samples, total changes in chemical composition, formation of material discontinuity, "micro-protuberance" with specific compositions, small crystals or coating of large sample surfaces, e.g. titanium. At this stage of our research, we are not trying to interpret the observed phenomena more deeply. In these tests, FTCPC apparatus was used in which the high pressure chamber was a capillary made of SS steel with a small internal diameter. Therefore, the test samples were regular cylinders (wire fragments) in addition to the $\mathrm{YMn}_{2}$ sample, which was a monocrystal with fairly regular geometric forms.

Palladium specimen $(99.96 \%$, in the shape of a rod of diameter $1 \mathrm{~mm}$ and length $111 \mathrm{~mm}$ ) and three rhenium specimens $(99.97 \%$, three rods of diameter $1 \mathrm{~mm}$ and length 13,25 , and $33 \mathrm{~mm}$ ) were placed in the capillary type DHPC under the pressure of gaseous deuterium of $\approx 3.0 \mathrm{kbar}$. In this experiment, irradiation by $\gamma$-quanta with the threshold energy $23 \mathrm{MeV}$ was carried out during $19.5 \mathrm{~h}\left(t=7 \times 10^{4} \mathrm{~s}\right)$ at the average electron beam current $11-12 \mu \AA$, and frequency in the range of $0.5-0.7 \times 10^{14} \mathrm{~s}^{-1}$.

Before opening the DHPC, the chamber pressure was measured to be 2860 bar, so a definite jump down of pressure was noted. The palladium wire and three rhenium specimens placed in the chamber could be extracted three days later, after deuterium desorption. The specimens, like the DHPC itself, proved to be highly activated, which did not permit X-ray microelement analysis to be performed

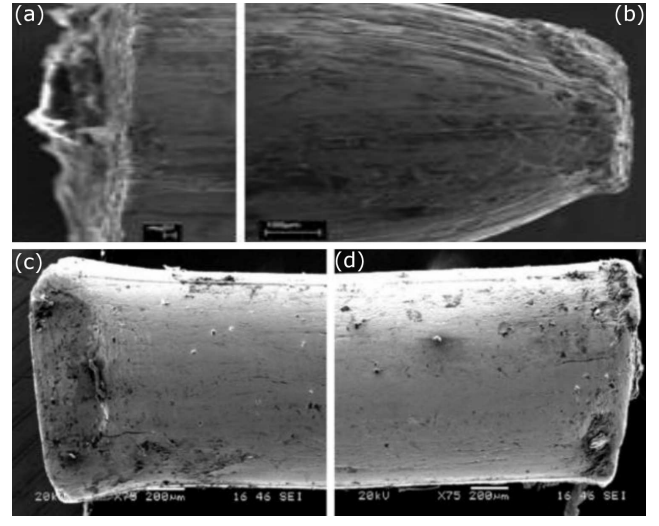

Fig. 6. SEM images of the left ends, i.e., (a) and (c), and the right ends, i.e., (b) and (d), of the $\mathrm{Pd}$ rod and of the Re rod, respectively. Left a place of entry of $\gamma$-quanta. Right — in reverse side. Both specimens are shown after irradiation at GNDR condition in $\mathrm{D}_{2}$ gas.

even after a long period allowed with the aim of decreasing the induced activity: four months for the palladium specimens and over eight months for the rhenium ones.

In Fig. 6, SEM images show places of entry and exit of $\gamma$-quanta for palladium and rhenium. As seen, the right edge of the Pd specimen (Fig. 6b) has undergone particularly considerable changes, namely the formation of an elongated part tapering towards the end from $1 \mathrm{~mm}$ to $0.46 \mathrm{~mm}$ in diameter with a strongly changed (eroded) frontal edge about $1000 \mu \mathrm{m}$ wide. At both the left (Fig. 6c) and right (Fig. 6d) ends of the Re wire, one can observe congealed blowouts from the surfaces which are smaller-scale and inhomogeneous in shape.

Figure 7 shows, as an example, SEM images of the crack and small crystals on the side surface of the palladium wire. Using the notation $x-$ (point $11 /$ point 12) in wt\%, where $x$ is the element concentration, the $x$ data can be determined for the microcrystal and bottom of the crack. Thus, element concentration data are as follows:

$$
\begin{array}{ll}
\mathrm{O}-(72.1 / 55.1) \%, & \mathrm{Na}-(1.0 / 0) \%, \\
\mathrm{Al}-(0.6 / 0.7) \%, & \mathrm{Si}-(0 / 26.9) \%, \\
\mathrm{~S}-(0.2 / 1.0) \%, & \mathrm{Cl}-(0.1 / 0.9) \%, \\
\mathrm{~K}-(5.8 / 1.3) \%, & \mathrm{Ca}-(0 / 1.8) \%, \\
\mathrm{Mn}-(0.6 / 0.8), & \mathrm{Fe}-(0.8 / 2.3) \%, \\
\mathrm{Ni}-(0 / 0.3) \%, & \mathrm{Zn}-(0 / 0.3) \%, \\
\mathrm{Pd}-(12.2 / 8.4) \%, & \mathrm{Re}-(6.6 / 0) \%, \\
\mathrm{Pt}-(0 / 0.2) \% . &
\end{array}
$$

\section{Effects of "micro-protuberances" on $\mathrm{V}, \mathrm{Cu}$, and Al surfaces}

These effects, observed at GDNR, are demonstrated in the case of irradiation of a system consisting of $\mathrm{V}-\mathrm{Cu}$ and $\mathrm{Al}-\mathrm{YMn}_{2}$ metallic specimens, see photographs in Fig. 8. 

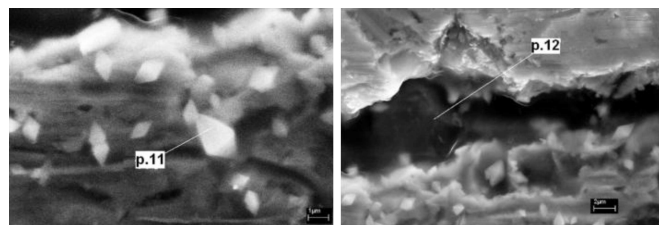

Fig. 7. SEM images of the crack (left part, point 11) and small crystals (right part, point 12) on the side surface of the palladium wire.

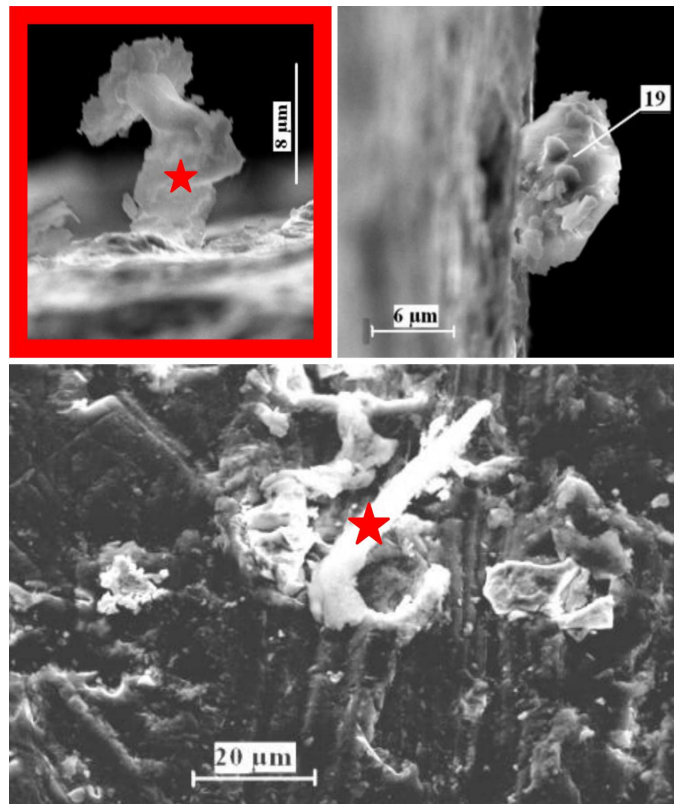

Fig. 8. Micro-protuberances and their element contents. For simplicity of notation, the weight $\%$ content was omitted. At starting point: $\mathrm{V}(99.999 \%)>\mathrm{C}(23), \mathrm{O}(7), \mathrm{Mg}(1), \mathrm{Al}(64), \mathrm{V}(1)$, $\mathrm{Cu}(4)$ (in point denoted by $\star$ ); $\mathrm{Cu}(99.999 \%)>$ $\mathrm{C}(24.0), \mathrm{O}(5.8), \mathrm{Mg}(1.2), \mathrm{Al}(31.6), \mathrm{Si}(1.2), \mathrm{Cu}(1.9)$, $\mathrm{Mn}(20.6)$, Y13.9 (in point no. 19); $\mathrm{Al}(99.999 \%)>$ $\mathrm{C}(24.9), \quad \mathrm{O}(8.1), \quad \mathrm{Na}(6.09), \quad \mathrm{Mg}(0.70), \quad \mathrm{Al}(18.2)$, $\mathrm{Si}(0.43), \quad \mathrm{P}(0.27), \quad \mathrm{S}(1.02), \quad \mathrm{Cl}(20.4), \quad \mathrm{K}(8.46)$, $\mathrm{Ca}(1.64), \mathrm{Fe}(0.38), \mathrm{Cu}(0.79)$ (in $\star)$.

Some divagations: our experiment of irradiation was a long-time process (several hours). Does protuberance take place in a short-time process (some picoseconds) in the form of complicated nuclear, local explosion (not a chemical energy source) in time typical for nuclear reactions or rise during the entire time of experiment?

\section{Structures and substances synthesis in $\mathrm{He}, \mathrm{D}_{2}, \mathrm{H}_{2}$, Xe system}

Due to some doubts of nuclear physicists concerning our results with $\mathrm{D}_{2}-\mathrm{Me}$ systems, the analogous studies investigating the feasibility of nuclear reactions were carried out in modified high-pressure hydrogen chambers (see Fig. 9). These were made with pure gas without any metallic samples inside, under irradiation with $10 \mathrm{MeV}$ braking $\gamma$-rays.

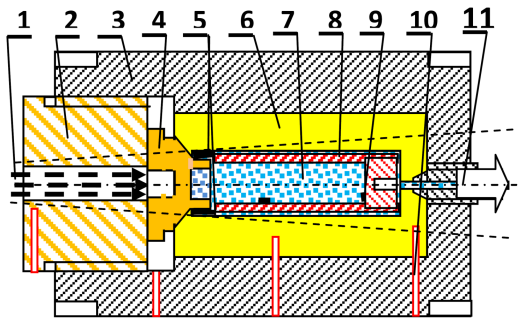

Fig. 9. Schematic of elements of the modified high pressure chamber: $1-\gamma$-quanta stream, $2-$ closing screw $(\mathrm{CuBe} 2), 3$ - reinforcing SS high pressure chamber body, $4-\mathrm{CuBe} 2$ "window-plug" $\left(58^{\circ} / 60^{\circ}\right.$ cones), 5 - places where mainly synthesized elements were observed, $6-\mathrm{CuBe} 2$ high pressure chamber, 7 - helium under high pressure, 8 - pure $\mathrm{Cu}$ sleeve, 9 - expected reaction product on pure $\mathrm{Cu}$ plug, 10 - temperature measurement, 11 high pressure.

The goal of this part of the paper is to present results on the synthesis of chemical elements under irradiation of dense molecular $\mathrm{H}_{2}, \mathrm{D}_{2}$ and atomic $\mathrm{He}$ and $\mathrm{Xe}$ gases, in the absence of metallic samples, with $\gamma$-rays of energies near $10 \mathrm{MeV}$. These studies have led mainly to the formation of considerably large particles due to nuclei-physics-chemical reactions.

\subsection{Mixture of $\mathrm{He}-\mathrm{D}_{2}$ after irradiation by electrons with energy of $10 \mathrm{MeV}$}

During electron irradiation, with electron current of $20 \mathrm{~mA}$, a quick - linearly in time - increasing pressure process was noted. When pressure attained a dangerous value (from $200 \mathrm{MPa}$ ) above $400 \mathrm{MPa}$ and calculated temperature (above $330^{\circ} \mathrm{C}$ ) after time irradiation of about $29 \mathrm{~min}$, the process was stopped. Surprisingly, the pressure, after about $2 \mathrm{~h}$, has attained a value which was close to normal. After demounting the pressure chamber, a serious destruction of the packing system (mainly the conical surface of element 4 in Fig. 9) was noted. We hope that, when the extraordinary times of the COVID-19 pandemic are over, this problem will be explained.

\subsection{HHPC filled with hydrogen under $p=1 \mathrm{kbar}$}

Such a pressure value of the order of $p=1 \mathrm{kbar}$ allows to obtain the atomic concentration of hydrogen $n_{H} \approx 2.952 \times 10^{22}$ at. $\mathrm{H} / \mathrm{cm}^{3}$ at its density $\rho_{H} \approx 0.0494 \mathrm{~g} / \mathrm{cm}^{3}$ [1], where only a manganin foil was placed in the HHPC chamber and there was no $\mathrm{Pd}$ rod inside). The chamber irradiation was carried out during $14 \mathrm{~h}\left(5.04 \times 10^{4} \mathrm{~s}\right)$. The electron beam energy was equal to $9.7 \mathrm{MeV}$ at the average current of 20-21 $\mu \AA$. During the opening of the HHPC, it spilled out eight small particles about $1 \mathrm{~mm}$ in size. Some of them were dark, and the remaining ones were of light color. When photographed with a special tool, all of the particles turned out to be transparent. 


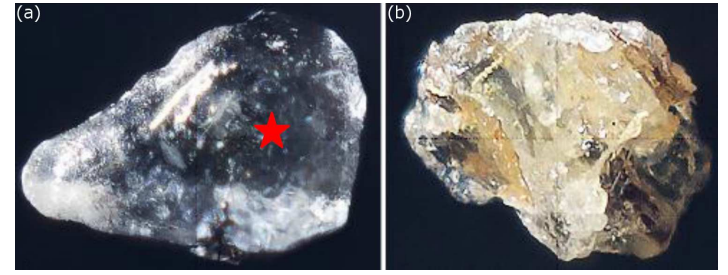

Fig. 10. Photos of the "dark" (a) and "light" (b) particles obtained in the $\mathrm{H}_{2}$ gas experiment with a size of about $700 \mu \mathrm{m}$ to $600 \mu \mathrm{m}$.

The photos in Fig. 10 obtained using a special photomicrography tool show the "dark" (a) and "light" (b) particles at about the same scale.

The element compositions were measured in the region pointed by $\star$ (for a dark particle). The collected data contain only light elements such as ${ }_{6} \mathrm{C}$, ${ }_{7} \mathrm{~N} \uparrow,{ }_{8} \mathrm{O},{ }_{9} \mathrm{~F} \uparrow,{ }_{10} \mathrm{Ne} \uparrow,{ }_{11} \mathrm{Na},{ }_{12} \mathrm{Mg},{ }_{13} \mathrm{Al},{ }_{14} \mathrm{Si},{ }_{15} \mathrm{P}$, ${ }_{16} \mathrm{~S},{ }_{17} \mathrm{Cl},{ }_{18} \mathrm{Ar} \uparrow,{ }_{19} \mathrm{~K},{ }_{20} \mathrm{Ca}$, and a heavier metal ${ }_{29} \mathrm{Cu}$. Here, a series of elements with a nucleus charge is changed by $\Delta Z=1$ from $Z=6$ (carbon) to $Z=20$ (calcium), where the volatile elements ${ }_{7} \mathrm{~N} \uparrow,{ }_{9} \mathrm{~F} \uparrow,{ }_{10} \mathrm{Ne} \uparrow,{ }_{18} \mathrm{Ar} \uparrow$ were not detected. Note that they could not have formed any chemical compounds. The same effect refers to the elements which are lighter than carbon and have a nucleus charge $Z<6$, i.e., ${ }_{1} \mathrm{D},{ }_{2} \mathrm{He},{ }_{3} \mathrm{Li},{ }_{4} \mathrm{Be}$ and ${ }_{5} \mathrm{~B}$. In fact, they cannot be registered by an X-ray microprobe spectrometer.

\subsection{Dense deuterium in DHPC under action of $\gamma$-rays}

As shown in Fig. 9a, the modified high pressure chamber was also used for the deuterium experiment where initially $p=2.2 \mathrm{kbar}$ and a relative deuterium purity is $\approx 10^{-6}$ [1]. The experiment was repeated under $p=3.05$ kbar with element 8 (see Fig. 9) made of beryllium bronze.

The modification of the DHPC consisted in the replacement of the viton sealing with the metal-tometal one (beryllium bronze $\mathrm{CuBe} 2$ ). This allowed to limit the chemical elements inside the high pressure chambers filled with gases $\mathrm{H}_{2}, \mathrm{D}_{2}$ and $\mathrm{He}$ only to $\mathrm{Cu}$ and $\mathrm{Be}$. The initial pressure was constant before irradiation during two weeks. The atomic density $n_{\mathrm{D}_{2}} \cong 2.1 \times 10^{2} 2 \mathrm{~mol} \mathrm{D} / \mathrm{cm}^{3}$ and the mass density $\rho_{\mathrm{D}_{2}} \cong 0.13 \mathrm{~g} / \mathrm{cm}^{3}$ [1]. The integrated electron dose at the target was $\approx 2.5 \times 10^{19} e^{-}$during the whole experiment. After the irradiation procedure, the pressure in the chamber remained constant during one month, so the leakage of gas was not observed.

The irradiation time was $t=1.76 \times 10^{5} \mathrm{~s}$ at the electron current $20-21 \mu \mathrm{A}$. During the irradiation at the stationary state due to growing temperature, an increase of deuterium pressure in the chamber was noted from initial $p_{0} \approx 2.085 \mathrm{kbar}$ at $T_{0}=293 \mathrm{~K}$ to $p_{\text {stat }} \approx 2.697 \mathrm{kbar}$ at $T_{\text {stat }}=343 \mathrm{~K}$. This means the increase "by jump" $\Delta p \approx 612$ bar.

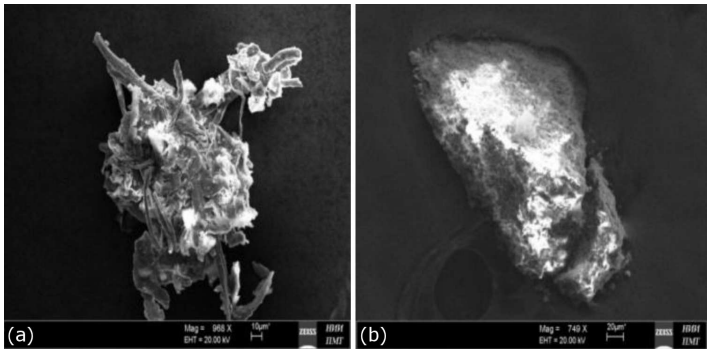

Fig. 11. Small dimension minerals obtained in the case of pure deuterium $\gamma$ irradiation [1]: (a) objects rich in carbon (57 at.\%) with typical complex geometry, (b) objects rich in oxygen (66 at.\%), with typical compact geometry.

Temperature $T_{\text {stat }}$ was measured at the surface of the pressure chamber made of beryllium bronze (see Fig. 9, position 10). inside the protecting sleeve made of stainless steel.

Taking into consideration the known ideal gases rule, the calculated pressure should be $p_{\text {calc }}=2.441 \mathrm{kbar}$.

Thus, the pressure change ought to be $\Delta p_{\text {cal }}=p_{\text {calc }}-p_{0}=356$ bar, as opposed to direct measurement yielding $\Delta p_{\text {meas }}=612$ bar. In this situation, we can suppose that the temperature inside the beryllium bronze chamber was higher, attaining the value $T_{\text {stat, cal }}=p_{\text {stat }} T_{0} / p_{0} \approx 379 \mathrm{~K}$. This means that it was $36 \mathrm{~K}$ higher. The interpretation of this difference is based on the supposition that some nuclear reactions took place during our experiment. It should be noted that in the case of the experiment with hydrogen, the calculated growth of pressure during the irradiation was in proper relation to the temperature measured at the surface of the pressure chamber made of beryllium bronze (see Fig. 9, element 6).

An accurate SEM and XRMPA observation of the inner surface of the high pressure chamber and inner surface of the split sleeve and closing element revealed 26 different objects which are described in a preprint published by the Joint Institute of $\mathrm{Nu}$ clear Research. Here, we will describe only the most interesting and representative results which can be interpreted.

As mentioned above, many different large particles were found after the irradiation. Here, we are going to present only two typical ones. One particle, with a large amount of carbon and of a rather nonregular shape, is shown in Fig. 11a. Another particle, with a large amount of oxygen and of a rather regular shape, is shown in Fig. $11 b$.

\subsection{Dense $\mathrm{He}_{2}$ in DHPC under $\gamma$-rays}

Upon opening the chamber, black foils with reinforcing needles were observed at the junction of the entrance window and reaction chamber (see Fig. 9, element 5). Part of the needles protruded from the foils as lengthy white rods of uniform 

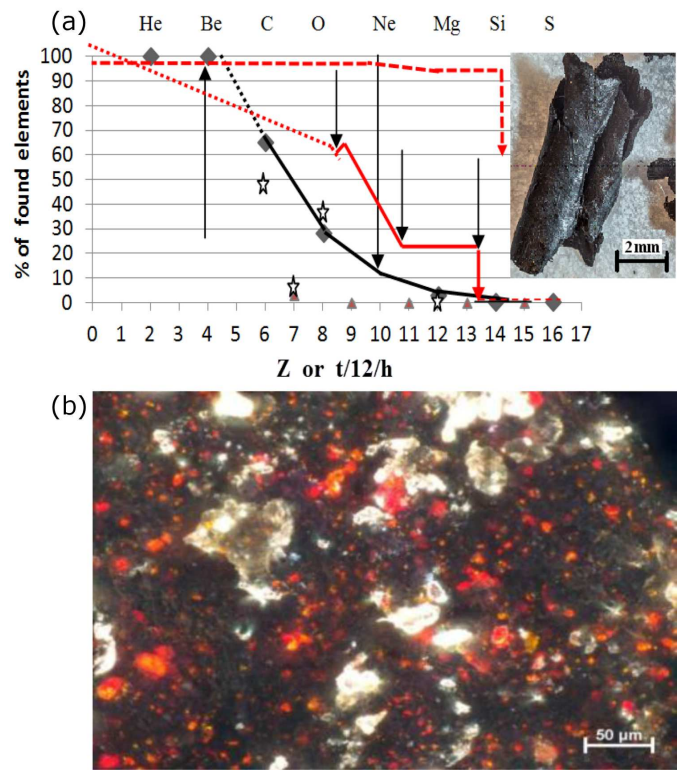

Fig. 12. (a) Illustration of the performed experiments with helium carried out using almost the same gamma irradiation procedure. Squares and the red line represent the first experiment data $(p=1.1 \mathrm{kbar})$; stars and the dotted line correspond to the second experiment ( $p=3 \mathrm{kbar}$ ). (b) One of the largest objects obtained in the first experiment and (c) a bottom part of the photo of a specimen fragment using the polarized light method (cooperation with Professor M. Szafran, the Chemical Faculty, WUT).

thickness. The foils were then placed on a clean sheet of (tracing) paper. In the place where the black foils were found, the tracing paper was soaked with exudation from the foils. Such exudation resembled synthetic oil or liquid hydrocarbons. In Fig. 12, the photos obtained using a special device for photomicrography show an array of round black foils which acquired this shape due to the cylindrical symmetry of the reaction chamber's entrance window. Using the element compositions measured at some points, it was possible to determine some regularities with the help of their mean values (see Fig. 12).

In the second helium experiment, we observed another kind of object, namely the main products of synthesis of similar chemical content that covered the inner surface of the split sleeve surface. This experiment is described in [1] and here only some most interesting and representative facts are considered.

Figure 12 summarizes the element compositions measured for different objects. The curves are given for two experiments with account of the mean values for the element compositions obtained using the MPRA method. The presented curves are different but have a similar character, i.e., a regular decreasing tendency of atomic concentration with a rising atomic number.
All of the synthesized particles here are the largest objects which have dielectric properties. According to the X-ray structural analysis, these particles have amorphous structures with a complex hydrocarbon composition that is absent in the reference library of the X-ray analysis. Due to its importance and for the purpose of greater reliability of the data, the structure of synthesized particles was analyzed using microscopes and X-ray micro-analyzers at two independent analytical centers. The mechanical properties of the large particles were not investigated. But there is a most intriguing problem with the electrical properties of the carbon-based structures which we obtained during all helium experiments. The latest measurements of the object presented in Fig. 12 (in (b) upper corner) [1] have shown a very large electrical resistivity $\rho=10^{10} \mu^{\prime} \Omega \mathrm{m}$, relative dielectric constant $\varepsilon_{r}=3-4$, low density $d=(1.2 \pm 0.2) \mathrm{g} / \mathrm{cm}^{3}$, large paramagnetic properties, having main chemical content $\mathrm{C}(62 \%), \mathrm{O}(31 \%), \mathrm{Mn}(3 \%)$. The structure is an open problem. In the compression probe, we have noted its micro elastic-brittle state with strength of $10 \mathrm{MPa}$ (approximate value) and temperature stability below $400^{\circ} \mathrm{C}$.

\subsection{Production of "foreign" chemical elements}

in condensed gases with LENR mechanism

LENR interpretation can be used for dense gases upon irradiation by $\gamma$ quanta [1]. As a result of this ionization of dense matter, in local regions, stable, electron-ion formations - the formation of "capsules" - are observed with a strong magnetic field $\boldsymbol{B}$ inside. "Capsules" contain a large quantity of atoms inside. The linear size of a "capsule" is estimated as $10^{-7} \mathrm{~cm}<L<10^{-3} \mathrm{~cm}$ [1]. LENR interpretation is made just for those "capsules". The theory of this process is described more widely in [3] as Mishinsky's effect, which is illustrated in Figs. 13 and 14.

In order to make investigation by Scherrer's powder method, it was necessary to prepare the proper powder of the probe. In the beginning, the powdering process seems to be normal, but at the end of the process a certain problem occurs. Some amounts of a coal phase named polyynes may exist in the material. The polymer character of the rest material was (a)
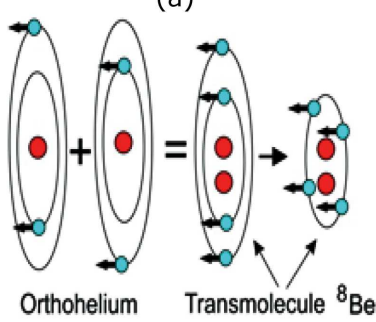

(b)

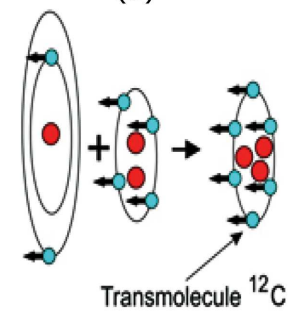

Fig. 13. Formation of transmolecules ${ }^{8} \mathrm{Be}$ and ${ }^{12} \mathrm{C}$ from ortho-helium ${ }^{4} \mathrm{He}$ [1]. 


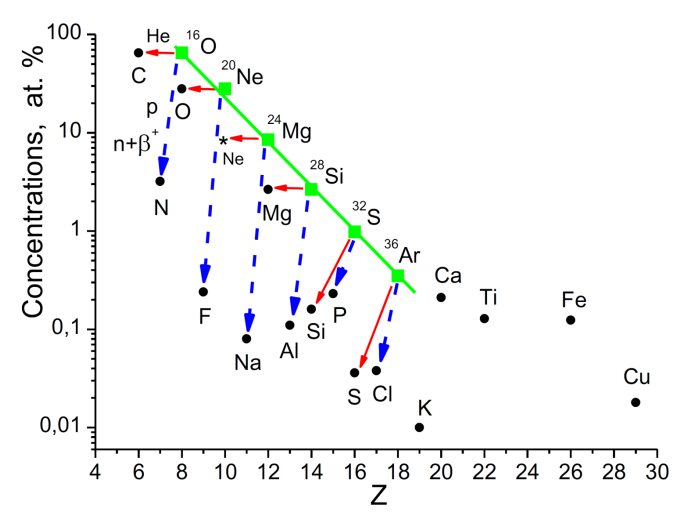

Fig. 14. Transformation of transmolecules $\left(n \bullet{ }^{4} \mathrm{He}\right)$ with helium, proton, or neutron emission.
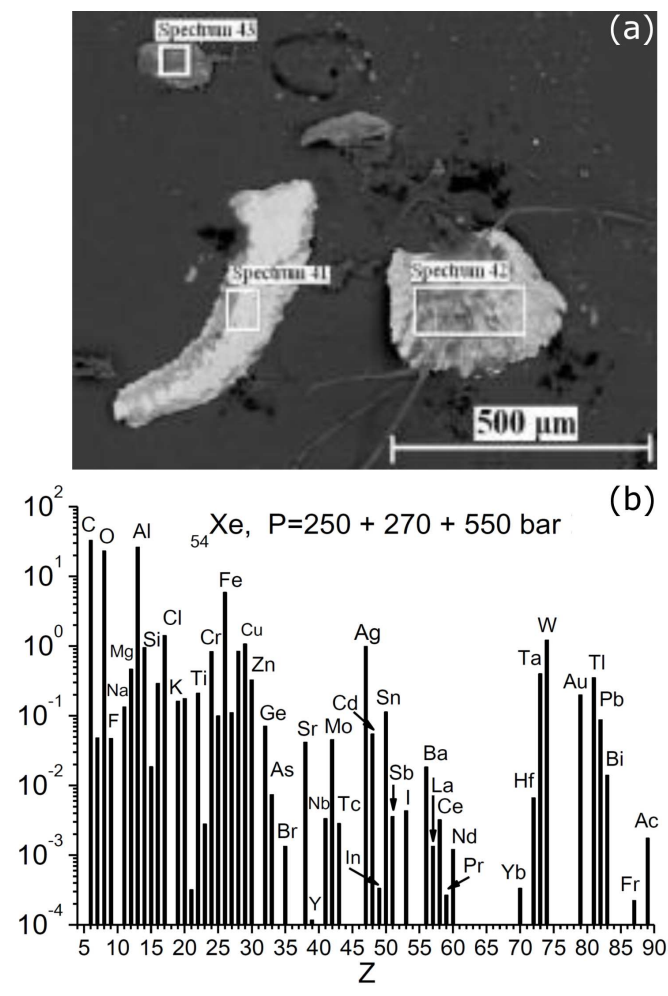

Fig. 15. Examples of generated particles of complicated chemical content after Xe irradiation.

observed. Lastly, the obtained pictures also suggest abnormal properties of obtained objects being a multiphase system because of physical and chemical reactions which are complicated in time and in places. Also, the possibility that the obtained compounds have even small organic substances in graphite-like objects will have a large meaning in cosmos deliberations.

Firstly, we have obtained, in simple laboratory conditions, the possibility of a production of carbon elements from dense gaseous helium, using only proper $\gamma$-quanta irradiation (without energy effect). Reaction $3 \alpha \gg^{12} \mathrm{C}$ plays a fundamental role in giant stars energy production (in conditions of several Mbar pressure and several millions ${ }^{\circ} \mathrm{C}$ of temperature, with energy effect, thanks to predicted by Hoyle - excited ${ }^{12} \mathrm{C}$ state equal to $E^{*}=7.656 \mathrm{MeV}$ ). Our results pointed out only some additional possibilities (conditions which may occur in the cosmos) for obtaining more heavy elements as $\mathrm{O}, \mathrm{C}, \mathrm{Mg}$, up to $\mathrm{Pb}$ from $\mathrm{He}$ or from other light gases, too. A more advanced theory of LENR has been presented lately by Mishinsky in his paper entitled "Towards a New Paradigm" [6]. Our investigations - as in the title, started in 2004 - had significant meaning here.

\subsection{Dense Xe in XeHPC under action of $\gamma$-rays}

Experiments performed [2] with dense Xe gave similar results. Examples of generated macroparticles are shown in Fig. 15.

\section{Summary}

The importance of our research, from the point of view of physical theories, is the justification of the formation of additional elements, e.g., $\mathrm{Pb}$ to protactinium and curium inclusive and new physical objects. From the point of view of applications, these are the foundations of new nano-, micro-, and macrotechnologies of new objects and elements, e.g., rare earths or maybe gold.

We are grateful to Professor G.V. Mishinsky for his full theoretical study (LENR) of pure He ("burned" on $\mathrm{C}, \mathrm{O}, \ldots$ ). Investigation of the $\mathrm{He}-\mathrm{D}_{2}$ system seems to confirm his theory [3]. A situation similar to our experiments (but at very high temperatures and pressures) has taken place in space (see works by Hoyle). Studies conducted by Żukowska (Faculty of Chemical Technology, WUT) have shown the presence - in trace amounts - of organic compounds in our facilities, and this can already have cosmological significance. More practical effects, mentioned above, should result in the form of a continuation of research presented here. In our experiments with metals, in their surface layers, some amounts of $\mathrm{MeD}_{x}$ or $\mathrm{MeH}_{x}$, for sure, were composed. It is also worth noting that considerable interest from organizers of conferences on materials science, nanotechnologies and related subjects has lately been noted, see [7].

\section{Acknowledgments}

All experiments were carried out in a very fruitful, friendly atmosphere as part of many-year close scientific cooperation of Polish and Russian teams (represented by R. Wiśniewski and A.Yu. Didyk) and were financed by both sides. We thank all the friendly people connected with us. Our special thanks go to the Editor of EPL (2012), Professor V. Zelevinsky (Michigan State University, USA), who provided the first constructive and very essential opinion on our not very typical problems. 
We would also like to extend our thanks to the organizers of the Extraordinary Congress of Polish Physicists, 2020 [8], especially to Professor Andrzej Wysmołek, and to express our sincere appreciation for Professor Jan Mostowski, the Editor-in-Chief of Acta Physica Polonica A.

\section{References}

[1] R. Wiśniewski, in: Principles and Applications in Nuclear Engineering, Eds. A. Rahman, M. Saleh, IntechOpen, London 2018, p. 49, (and references therein).

[2] A.Y. Didyk, G.G. Gulbekian, G.V. Mishinsky, R. Wiśniewski, J. Phys. Sci. Appl. 6, 18 (2016).

[3] R. Wiśniewski, G.V. Mishinsky, T. Wilczyńska, Z. Żukowska, A. Rostocki, Acta Phys. Pol. B Proc. Suppl. 13, 961 (2020).
[4] R. Wiśniewski, G. Mishinsky, T. Wilczyńska-Kitowska, Z. Żukowska, A.J. Rostocki, 45th Meeting of Polish Physicists, Cracow 2019, poster.

[5] R. Wiśniewski, G.V. Mishinsky, T. Wilczyśka-Kitowska, Postępy Fizyki 64, 76 (2013).

[6] G.V. Mishinsky, RENSIT 12, 529 (2020).

[7] R. Wiśniewski, G.V. Mishinsky, T. Wilczyńska-Kitowska, World Congress on Materials Science and Engineering, Amsterdam 2018, keynote presentation.

[8] T. Wilczyńka-Kitowska, R. Wiśniewski, A.Yu. Didyk, G.V. Mishinsky, A.J. Rostocki, Conference Materials of the Extraordinary Congress of Polish Physicists, Warsaw 2020, posters 100 and 112 . 